MATEC Web of Conferences 47, 05011 (2016)

DOI: $10.1051 /$ matecconf/20164705011

(C) Owned by the authors, published by EDP Sciences, 2016

\title{
The Strength, Leachabilty and Microstructure Characteristics of Chromium Contaminated Stabilised Sediment
}

\author{
Mohammed Kabir Aliyu ${ }^{1, a}$, Ahmad Tarmizi Abd Karim ${ }^{1}$ and Chan Chee Ming ${ }^{1}$ \\ ${ }^{1}$ Faculty of Civil and Environmental Engineering, Universiti Tun Hussein Onn Malaysia, 86400 Parit Raja, Johor, \\ Malaysia
}

\begin{abstract}
The effect of replacing cement with rice husk ash (RHA) on compressive strength and leachability of Chromium stabilised sediments was investigated. Artificially contaminated sediment was prepared by spiking sediment with solution of Potassium dichromate (K2Cr2O7) to achieve an average of $1000 \mathrm{ppm}$ target concentration. Cement was added at $10 \%$ and rice husk ash at $5 \%, 10 \%, 15 \%$ and $20 \%$ to the total dry weight of the mixture, which were then cured at room temperature $\left(27 \pm 3^{\circ} \mathrm{C}\right)$ and humidity of $75 \pm 5 \%$ for 7,14 and 28 days. The addition of RHA with cement to the spiked sediment increased the compressive strength (UCS) of solidified sample with increase in curing period. The reaction products and crystalline mineral phases were identified using X-ray diffraction (XRD) which shows the formation of various crystalline phases of the treated sediment after 28 days which explain the mechanisms responsible for immobilization of chromium under study. The UCS values of solidified samples at 7, 14 and 28 days exceeded the minimum landfill disposal limits of $0.34 \mathrm{~N} / \mathrm{mm} 2$ $(340 \mathrm{kPa})$. It was observed that leaching of $\mathrm{Cr}$ (VI) was higher in acetic acid medium (TCLP) as compared to deionized water (DIW) medium. The leached chromium concentrations in the two different leachates (acetic acid, and deionized water) were all below the regulatory limits of $5 \mathrm{mg} / \mathrm{l}$ of U.S EPA. Results have indicated that the partial replacement of cement with RHA in the binder system has increased the strength and reduced leachability of chromium in the treated compared to untreated sediment samples.
\end{abstract}

\section{Introduction}

Solidification/Stabilisation $(\mathrm{S} / \mathrm{S})$ is a treatment technique by which contaminated soils, sediments or waste are mixed with a binder and/or specific additives with the aim of decreasing the mobility of the toxic contaminants by increasing the $\mathrm{pH}$ and fully or partially binding the contaminants in the solid matrix (stabilisation), but also of improving the physical properties (strength, compressibility, permeability and durability) of the final treatment products (solidification) [1].

The wide spread use of chromium has resulted in the contamination of soils and water. Chromium contamination is of great concern due to its toxic, mutagenic, and carcinogenic nature. The chromium is generated from steel and other alloy's production, pigments, chrome plating and leather tanning industries. Among the various forms of chromium, $\mathrm{Cr}$ (VI) is the form which is commonly found at contaminated sites and most important one because of its toxicity, solubility, and mobility

\footnotetext{
${ }^{\text {a }}$ Corresponding author : hf110153@siswa.uthm.edu.my
} 
characteristics [2, 3]. It can cause skin rashes, nose irritation, stomach upsets, respiratory problems, weakened immune systems, kidney and liver damage, lung cancer and sometimes even death.

X-ray diffraction (XRD) has been found to be a useful application to characterize the crystalline phases of the solidified wastes $[4,5]$. Information from such studies can be used successfully to obtain the immobilization mechanisms and reactions that occur in an $\mathrm{S} / \mathrm{S}$ process $[4,6]$. At present, Toxicity characteristic leaching procedure (TCLP) is used by the US EPA to evaluate whether a particular S/S process is effective in treating a given waste. The TCLP limit for chromium is $5 \mathrm{mg} / \mathrm{l}$. Factors such as waste form, binder system, curing time and cement-to-waste ratio have been identified to affect the leachability of a waste after an S/S treatment [4, 7-9].

\section{Experimental Program}

\subsection{Materials}

$\mathrm{TiO}_{2}$ The main source of data for this study are sediments taken from Sembrong river at a site located between geographical coordinates of latitude $1^{\circ} 52^{\prime} .18 .44^{\prime \prime} \mathrm{N}$ and longitude $103^{\circ} 06^{\prime} 15.71^{\prime \prime}$ E, at Parit Sempadan, Parit Raja near Universiti Tun Hussein Onn Malaysia (UTHM). Holcim Top standard cement was used for this study. This type of cement is one of the cement that its quality complies with the Malaysian standard MS 522:2007. This type of cement is usually used as the main binder for ordinary construction and is readily available and also is environmentally friendly due to the reduced $\mathrm{CO}_{2}$ emission when it is produced. The rice husk used was burnt at a controlled temperature of $700^{\circ} \mathrm{C}$ in the furnace for a period of 6 hours, with a heating rate of $5^{\circ} \mathrm{C} / \mathrm{min}$ and then it was left overnight to cool. The burnt ash was then ground to produce ash size less than $75 \mu \mathrm{m}$.

\subsection{Sediment contamination procedure}

The natural sediment contains very low (below detection limits) concentration of chromium. Therefore to obtain synthetic contaminated sediment, the dried sediment samples was spiked with potassium dichromate $\left(\mathrm{K}_{2} \mathrm{Cr}_{2} \mathrm{O}_{7}\right)$ to obtain approximately $1000 \mathrm{ppm}$ target concentration to simulate worst case contamination scenario at a site prior to treatment. The contaminated sediment was prepared by mixing pre - determined amount of the potassium dichromate $\left(\mathrm{K}_{2} \mathrm{Cr}_{2} \mathrm{O}_{7}\right)$ with deionized water prior to addition into the sediment. The sediment sample was then mixed thoroughly and allowed to mellow foe a period of 7 days to ensure homogeneous distribution of the contaminant in the sediment.

\subsection{Solidification/stabilisation sample preparation}

The chromium contaminated sediment samples were mixed with the required amount of cement and/or RHA. Although based on current practice, cement has been added to soil from 5\% to 20\% [10]. It was decided to experiment with $10 \%$ cement to total mixture while rice husk ash was added at $5 \%$ to $20 \%$ to the total dry weight of the mixture. The sediment, cement and RHA were then thoroughly mixed in a clean Baker stand mixer. The water to cement ratio used was 0.4 for all the mixing process. The mixture was then transferred to a custom-made plastic cylindrical mould of $25 \mathrm{~mm}$ diameter and $50 \mathrm{~mm}$ height and compacted in 3 layers of $10 \mathrm{~g}$ each, each layer was compressed and compacted with a custom made miniature compaction tool and compressed for 25 blows at each layer. The sample specimen was then gently pushed out of the mould and wrapped with a cling film and kept at relative humidity of not less than $95 \%$ in tightly closed plastic curing box at $27 \pm 2^{\circ} \mathrm{C}$ for different periods of up to one month, the specimens were left to cure for 7, 14 and 28 days and UCS test was carried out on the specimens at the above mentioned curing days. A detail of the mix ratios of the specimens for the unconfined compressive strength (UCS) test is given in Table 1. 
Table 1. Mix ratios for unconfined compression test (cement + RHA + spiked sediments).

\begin{tabular}{cccccc}
\hline Mix Ratios Symbol & Sediment $(\%)$ & Cement (\%) & RHA (\%) & w/c Ratio \\
\hline $100: 0: 0$ & 100 & 0 & 0 & 0.4 \\
\hline $90: 10: 0$ & 90 & 10 & 0 & 0.4 \\
\hline $85: 10: 5$ & 85 & 10 & 5 & 0.4 \\
\hline $80: 10: 10$ & 80 & 10 & 10 & 0.4 \\
\hline $75: 10: 15$ & 75 & 10 & 15 & 0.4 \\
\hline $70: 10: 20$ & 70 & 10 & 20 & 0.4 \\
\hline
\end{tabular}

\subsection{Compressive strength}

Unconfined compressive strength test (UCS) was conducted to evaluate the strength of the mixture of rice husk ash with cement and the chromium spiked sediment samples at higher stress. The test was conducted in accordance with BS 1377 (1990), part 7[11]. The compressive strength of the solidified samples was determined after 7,14 and 28 days of moisture curing. Specimen tested for UCS were collected and dried in the oven at $105^{\circ} \mathrm{C}$ for 24 hours before being crushed to pass through a $1 \mathrm{~mm}$ sieve prior to TCLP and deionised water leaching tests.

\subsection{Leachability and XRD analysis}

The leaching test was carried out in acidic as well as in distilled water medium at 7, 14 and 28 days of curing using the toxicity characteristics leaching procedure (TCLP) in accordance with EPA method 1311 (USEPA, 1992). Samples were ground and passed through a No. 40 sieve $(0.425 \mathrm{~mm})$ prior to the TCLP tests. Precisely, 5g of the crushed stabilised sediments was placed in 500-ml plastic bottles and mixed with a designated $100 \mathrm{ml}$ of TCLP extraction fluid, For this research TCLP extraction fluid No. 2 was used because the $\mathrm{pH}$ of all the samples were above 5.0 even after the addition of $3.5 \mathrm{ml} 1 \mathrm{M}$ $\mathrm{HCl}$ and heated for 10 minutes at $50 \pm 5^{\circ} \mathrm{C}$. The leaching solution was designed to simulate the worst case leaching conditions on disintegrated landfill waste due to prolonged aging effects. The extraction fluids used are acetic acid ( $\mathrm{pH} 2.88 \pm 0.05)$, and distilled water (DIW) $(\mathrm{pH}=7.0 \pm 0.1)$ was used to examine the impact of a non- aggressive solution, and it is used here as a control. It is useful to evaluate the potential of a material when exposed to normal precipitation, all at a solid - liquid ratio of 1:20 by weight of the crushed sediment.

XRD was used to investigate the crystalline mineral phases responsible for Chromium immobilisation in the stabilised sediment samples. Samples were ground to fine powders and

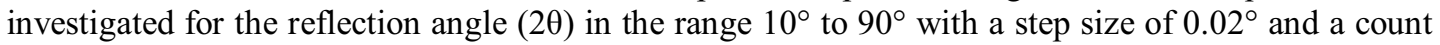
time of $15.4 \mathrm{~s}$ per step. Step-scanned X-ray diffraction data was collected with XRD Bruker D8 Advance machine. The XRD analysis was conducted at $40 \mathrm{kV}$ and $40 \mathrm{~mA}$ using a diffracted beam graphite-monochromator with $\mathrm{Cu}$ radiation. XRD patterns were qualitatively analysed and interpreted using Eva software and reference data base from the International Centre for Diffraction Data (ICDD) data base.

\section{Results and Discussion}

The effect of adding RHA and cement to the chromium contaminated sediment on the compressive strength and leachability of chromium was investigated. The results are reported and discussed in the following sections. 


\subsection{Unconfined compressive strength}

The strength of the solidified sediment samples was measured after 7, 14 and 28 days of curing. The results of the UCS are shown in Table 2. The strength was dependent on the amount of RHA added in the binder system. The highest strength of $4780 \mathrm{kPa}$ was obtained with mix ratio $\mathrm{Cr} 28$ 80:10:10 (80\% Chromium spiked sediment, $10 \%$ cement and 10\% RHA at 28 days of curing). The least compressive strength was indicated by the control sample Cr7.100:0:0 (100\% Chromium spiked sediment, 0\% Cement and $0 \%$ RHA at 7 days of curing) which was $234.6 \mathrm{kPa}$. However, except for the control sample which the strength was $234.6 \mathrm{kPa}$, the strength in each case was more than the minimum strength required $340 \mathrm{kPa}$ as per the landfill disposal limit. This is because the calcium hydroxide crystal produced during cement hydration was consumed during the pozzolanic reaction of RHA, which occurred mostly during these curing durations, and as a result, the secondary calcium silicate hydrate $(\mathrm{CSH})$ gel was formed. It is believed that this secondary $\mathrm{CSH}$ gel contributes to the additional strength for the mixture other than the primary CSH gel obtained from the hydration of cement [12].

Table 2. UCS of solidified/stabilised chromium spiked samples throughout 28 days of curing.

\begin{tabular}{lccc}
\hline \multirow{2}{*}{ Mix Ratios } & \multicolumn{3}{c}{ Unconfined Compressive Strength (kPa) } \\
\cline { 2 - 4 } & $\mathbf{7 ~ d a y s}$ & $\mathbf{1 4}$ days & $\mathbf{2 8}$ days \\
\hline $100: 0: 0$ & 234.6 & 377.2 & 523 \\
\hline $90: 10: 0$ & 1614 & 2179 & 2379 \\
\hline $85: 10: 5$ & 2341 & 2844 & 3407 \\
\hline $80: 10: 10$ & 3003 & 3071 & 4780 \\
\hline $75: 10: 15$ & 3484 & 3639 & 4505 \\
\hline $70: 10: 20$ & 3075 & 4142 & 3297 \\
\hline
\end{tabular}

\subsection{Leachability and XRD analysis}

The leachability tests of solidified samples containing $\mathrm{Cr}$ (VI) were carried out at various mix ratios and curing time (7, 14 and 28 days). As can be seen in Table 3, it will be observed that leaching of $\mathrm{Cr}$ (VI) was higher in acetic acid (TLCP) medium as compared to deionized water (DIW) medium. The leachability of chromium was reduced from $2.197 \mathrm{mg} / 1$ to 0 (below detection limits) for the TCLP, and $0.259 \mathrm{mg} / \mathrm{l}$ to 0 (below detection limits) for the DIW leachates. The leached chromium concentrations in the two different leachates (Acetic acid, and deionized water) were all below the regulatory limits of $5 \mathrm{mg} / \mathrm{l}$. The chromium concentration in the leachates of cement/RHA was less compared to the control sample which may be due to binding of $\mathrm{Cr}$ (VI) by cement/RHA [13]. The percentage of chromium leached out in the TCLP was between 1.94 to $0 \%$ for all the mix ratios and at curing days of 7, 14 and 28 days, while for the deionized water the percentage of chromium leached out was between 0.2 to $0 \%$.

Table 3. The concentration of chromium in the TCLP and DIW leachates at 7, 14 and 28 days.

\begin{tabular}{lcccccc}
\hline Mix ratios & $\begin{array}{c}\text { Conc. at 7 } \\
\text { days for } \\
\text { TCLP } \\
\text { (mg/l) }\end{array}$ & $\begin{array}{c}\text { Conc. at 7 } \\
\text { days for } \\
\text { DIW(mg/l) }\end{array}$ & $\begin{array}{c}\text { Conc. at 14 } \\
\text { days for } \\
\text { TCLP (mg/l) }\end{array}$ & $\begin{array}{c}\text { Conc. at 14 } \\
\text { days for } \\
\text { DIW(mg/l) }\end{array}$ & $\begin{array}{c}\text { Conc. at } \\
\text { 28 days } \\
\text { for TCLP } \\
\text { (mg/l) }\end{array}$ & $\begin{array}{c}\text { Conc. at 28 } \\
\text { days for } \\
\text { DIW(mg/l) }\end{array}$ \\
\hline $100: 0: 0$ & 1.224 & 0.043 & 1.121 & 0.019 & 1.482 & 0.043 \\
\hline $90: 10: 0$ & 0.011 & 0 & 2.048 & 0.259 & 1.806 & 0.106 \\
\hline $85: 10: 5$ & 2.197 & 0.200 & 1.942 & 0 & 1.821 & 0.079 \\
\hline $80: 10: 10$ & 1.888 & 0 & 1.344 & 0 & 1.474 & 0.040 \\
\hline $75: 10: 15$ & 0.0180 & 0 & 1.174 & 0 & 0 & 0 \\
\hline $70: 10: 20$ & 0.0184 & 0 & 1.391 & 0 & 1.118 & 0.009 \\
\hline
\end{tabular}




\section{IConCEES 2015}

The results of X-ray diffraction show the formation of various crystalline mineral phases after 28 days of curing, it was performed on the treated chromium spiked sediment after 28 days of curing for the sample Cr28d.85:10:5 (85\% Chromium spiked sediment, 10\% cement and 5\% RHA at 28 days) and Cr28d.75:10:15. (75\% Chromium spiked sediment, 10\% cement and 15\% RHA at 28 days ). It can be observed in Figure 1 which shows the XRD pattern of Cr28.85:10:5 and Cr28.75:10:15 after 28 days of curing. The most prominent peaks in the Chromium spiked sample $(\mathrm{Cr} 28.85 .10 .5)$ were those of Kaolin at $2 \theta$ of $12.41^{\circ}$ and $24.90^{\circ}$, Quartz at $2 \theta$ of $20.86^{\circ}, 26.65^{\circ}, 50.14^{\circ}, 59.96^{\circ}$, Pyrite at $2 \theta$ of $33.02^{\circ}, 40.74^{\circ}, 47.39^{\circ}$ and $56.27^{\circ}$, Montmorillonite at $2 \theta$ of $64.36^{\circ}$ and $73.57^{\circ}$, Muscovite at $2 \theta$ of $34.98^{\circ}, 42.38^{\circ}, 45.83^{\circ}$ and $61.79^{\circ}$ and for the chromium phase were observed at $2 \theta 19.93^{\circ}, 26.91^{\circ}$, $29.48^{\circ}$ and $37.76^{\circ}$. Subsequent to treatment with the Cement/RHA (Cr28.75:10:15) the peaks of Chromium were not detected, but only for Chromium oxide, Portlandite $\mathrm{Ca}(\mathrm{OH})_{2}$, one of the cement hydration products, was identified at $2 \theta$ of $17.69^{\circ}$ and $36.50^{\circ}$. The peaks of ettringite (E) are also observed at $15.77^{\circ}$ and $34.53^{\circ}$. The chromium ettringite phase is a low-solubility product which restricts $\mathrm{Cr}$ (VI) leaching in the (Cr28.75:10:15) and may be due to addition, substitution or precipitation of new components as observed by earlier workers [14]. Kaolinite peaks were observed at $2 \theta$ of $12.35^{\circ}, 24.86^{\circ}$ and $38.34^{\circ}$, Pyrite at $2 \theta$ of $33.04^{\circ}, 47.36^{\circ}$ and $56.13^{\circ}$, montmorillonite peak at $2 \theta 61.82^{\circ} .2 \theta$ of $33.04^{\circ}, 47.36^{\circ}$ and $56.13^{\circ}$, montmorillonite peak at $2 \theta 61.82^{\circ}$.

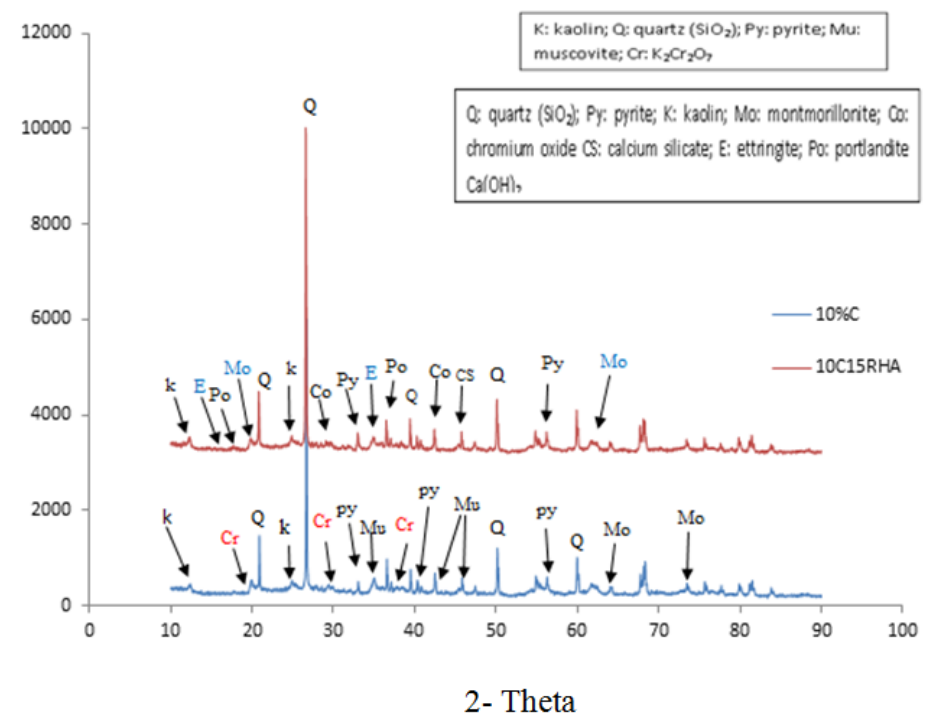

Figure 1. XRD patterns of chromium spiked sediment for cr28d.85:10:5 and cr28d.75:10:15 after 28 days.

\section{Conclusions}

The following conclusions can be drawn based on the experimental study:

i. The compressive strength of chromium spiked sediment was in the range of $234.6 \mathrm{kPa}$ to 4780 $\mathrm{kPa}$, there was enormous increase in the compressive strength with increase in the rice husk ash content of $5-20 \%$, as the number of days of curing increases. The maximum strength was obtained between 15-20\% RHA additions. While minimum strength was obtained for the control samples ( $0 \%$ cement / 0\% RHA). All the UCS values obtained for all the solidified sediment samples exceeded the Landfill disposal limit of $0.34 \mathrm{Nmm} 2(340 \mathrm{kPa})$ for a waste, except for the control sample at 7 days which has the value of $234.6 \mathrm{kPa}$ slightly below the regulatory limit.

ii. Leachability tests (TCLP and Deionised water) conducted on the crushed Stabilized/Solidified sediment samples indicated that chromium in the leachates of acetic acid and deionized water were either undetectable or appreciably below the leachability limits. The retention capacity of 
chromium spiked sediment sample was in the range of $97 \%$ to $100 \%$ for the TCLP and $100 \%$ for Deionised water leaching test.

iii. The XRD analysis of the stabilised chromium spiked sediment showed reaction products and various peaks of $\mathrm{Cr} 28 \mathrm{~d} .75: 10: 15$ and $\mathrm{Cr} 28 \mathrm{~d} .85: 10: 5$ samples. The retention of chromium by the $\mathrm{S} / \mathrm{S}$ in the cementitious matrix of cement-RHA mixture is due to addition, substitution (Crettringite, $\mathrm{Cr}-\mathrm{CSH})$ or precipitation of new components. Portlandite $\mathrm{Ca}(\mathrm{OH})_{2}$ was identified for the treated samples after 28 days indicating pozzolanic reactions were not over.

\section{References}

[1] A. Antemir, C.D. Hills, P.J. Carey, M.C. Magnie and A. Polettini, Investigation of 4-year-old stabilised/solidified and accelerated carbonated contaminated soil, J. of Hazardous Materials, 181(1), 543-555, (2010).

[2] S.A. Katz and H. Salem, The Biological and Environmental Chemistry of Chromium, VCH Publishers, New York, (1994).

[3] S. Wang and C. Vipulanandan, Solidification/stabilization of Cr (VI) with cement: Leachability and XRD analyses, Cement and Concrete Research, 30(3), 385-389, (2000).

[4] C. Vipulanandan and S. Wang, Remediation of hexavalent chromium contaminated soil, Proc. of In-Situ Remediation of the Geoenvironment, ASCE, New York, 363-373, (1997).

[5] C. Vipulanandan and S. Krishnan, Leachability and biodegradation of high concentrations of phenol and o-chlorophenol, Hazardous Waste and Hazardous Materials, 10(1), 27-47, (1993).

[6] A. Roy, H.C. Eaton, F.K. Cartledge and M.E. Tittlebaum, Solidification/stabilization of a heavy metal sludge by a Portland cement/fly ash binding mixture, Hazardous Waste and Hazardous Materials, 8(1), 33-41, (1991).

[7] P.L. Bishop, Contaminant leaching from solidified-stabilized wastes. Emerging Technologies in Hazardous Waste Management II, American Chemical Society, Washington, (1991).

[8] S.Y. Wang and C. Vipulanandan, Leachability of lead from solidified cement-fly ash binders, Cement and Concrete Research, 26(6), 895-905, (1996).

[9] C.K. Lin, J.N. Chen and C.C Lin, An NMR and XRD study of solidification/stabilization of chromium with Portland cement and $\beta-C 2$ S, J. of Hazardous Materials, 48(1), 137-147 (1996).

[10] R. Malviya, and R. Chaudhary, Factors affecting hazardous waste solidification/stabilization: A review, J. of Hazardous Materials, 137(1), 267-276 (2006).

[11] BS 1377-7, Methods of Tests for Soils for Civil Engineering Purposes, British Standards Institution, London, (1990).

[12] R.J. Detwiler, J.I. Bhatty and S. Battacharja, Supplementary Cementing Materials for Use in Blended Cements, Portland Cement Association, Illinois, (1996).

[13] N. Jain, Solidification and Leachability of Cr (VI) in rice husk ash-blended cement, ISRN Civil Engineering, 2011, 1-6, (2011).

[14] V.L. Bonavetti, V.F. Rahhal and E.F. Irassar, Studies on the carboaluminate formation in limestone filler-blended cements, Cement and Concrete Research, 31(6), 853-859, (2001). 